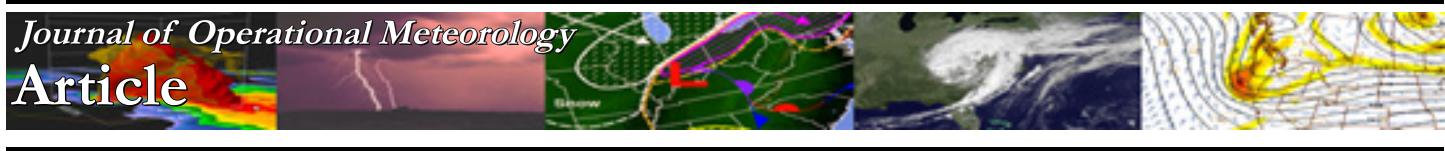

\title{
Applications of the 16 Spectral Bands on the Advanced Baseline Imager (ABI)
}

\author{
TIMOTHY J. SCHMIT \\ NOAA/NESDIS Center for Satellite Applications and Research Advanced Satellite Products Branch, Madison, Wisconsin \\ SCOTT S. LINDSTROM \\ Cooperative Institute for Meteorological Satellite Studies (CIMSS), University of Wisconsin-Madison, Madison, Wisconsin \\ JORDAN J. GERTH \\ Cooperative Institute for Meteorological Satellite Studies (CIMSS), University of Wisconsin-Madison, Madison, Wisconsin \\ MATHEW M. GUNSHOR \\ Cooperative Institute for Meteorological Satellite Studies (CIMSS), University of Wisconsin-Madison, Madison, Wisconsin
}

(Manuscript received 18 October 2017; review completed 5 March 2018)

\begin{abstract}
The Advanced Baseline Imager (ABI) on the Geostationary Operational Environmental Satellite (GOES)-R series has 16 spectral bands. Two bands are in the visible part of the electromagnetic spectrum, four are in the near-infrared, and ten are in the infrared. The ABI is similar to advanced geostationary imagers on other international satellite missions, such as the Advanced Himawari Imager (AHI) on Himawari-8 and -9. Operational meteorologists can investigate imagery from the ABI to better understand the state and evolution of the atmosphere. Various uses of the ABI spectral bands are described. GOES-R was launched on 19 November 2016 and became GOES-16 upon reaching geostationary orbit. GOES-16 is the first in a series of four spacecraft that will host ABI. GOES-16 became operational on 18 December 2017, in the GOES-East location. The ABI improvement is two orders of magnitude more than the legacy GOES imager due to more spectral bands and finer spatial and temporal resolutions.
\end{abstract}

1. The Advanced Baseline Imager (ABI) on the Geostationary Operational Environmental Satellite (GOES)-R series

The ABI on the GOES- $R$ series has 16 spectral bands, with two bands in the visible part of the electromagnetic spectrum, four in the near-infrared (NIR), and ten in the infrared (IR). These ABI spectral bands used individually or together can inform the analyst of unique characteristics of the Earth and atmosphere that may be difficult to discern from other types of observations. The diverse applications for each of the spectral bands are explained in this paper. GOES-R, the first satellite in a series of four spacecraft that the United States will launch over the coming decade, became GOES-16 when it achieved geostationary orbit following launch on 19
November 2016. The longitude of the on-orbit checkout phase was approximately $89.5^{\circ} \mathrm{W}$. GOES-16 became operational on 18 December 2017, in the GOES-East location (approximately $75.2^{\circ} \mathrm{W}$ ). The GOES-R series will be operational through the mid to late 2030s. The next satellite in the GOES-R series, GOES-S, will likely reach the GOES-West location (approximately $137^{\circ} \mathrm{W}$ ) in late 2018.

There are several international missions that fly, or plan to fly, an advanced imager from the geostationary orbit, including the Japan Meteorological Agency's Himawari-8/9 and the Korea Meteorological Administration's Geo-KOMPSAT-2A. The European Organisation for the Exploitation of Meteorological Satellites (EUMETSAT) led the way, with the 12band Spinning Enhanced Visible and Infrared Imager 
(SEVIRI) on the Meteosat Second Generation (MSG) first launched in 2002 (Schmetz et al. 2002). The Flexible Combined Imager on the Meteosat Third Generation (MTG) continues on the improvements and includes two IR bands at approximately $1 \mathrm{~km}$ spatial resolution (at the satellite sub-point).

The performance of the ABI is much improved compared to the legacy GOES imager spectrally, spatially, and temporally. The improvement is consequential for the availability and quality of the imagery. With the ABI on the GOES-R series, the number of spectral bands increased from five to 16 , including NIR bands for the first time on the GOES. The spatial resolution is four times finer; the highest spatial resolution band in the visible is nominally $0.5 \mathrm{~km}$ at the satellite subpoint. The coverage rate is approximately five times faster because of the increased number of detectors per band on the ABI (legacy GOES has two detectors for each infrared band, whereas ABI has hundreds) so that the instrument can simultaneously scan large swaths of the earth. The large detector array also allows for the ABI to dwell longer on each field of view, which yields improved Signal-to-Noise-Ratio (SNR) for the visible and near-infrared bands and improved Noise Equivalent delta Temperature (NEdT) for most of the IR bands. For example, the NEdT on the $6.9 \mu \mathrm{m}$ ABI water vapor band is approximately five times better than the similar band on the legacy GOES Imager.

Contributing to the improvement in image frequency and quality, the Image Navigation and Registration and radiometric quality is better. For example, each spectral band has more precision (i.e., more bits per pixel). There are 12 bits per pixel for all ABI band imagery files except for ABI band $7(3.9 \mu \mathrm{m})$, which has 14 bits per pixel. The ABI also has an improved dynamic range and improved calibration (i.e., accuracy). The ABI has on-board visible calibration so that the imagery will not fade as the detectors age as has happened with the legacy GOES imager (Schmit et al. 2017). This cumulatively results in a 100 times improvement more than the legacy GOES imager in terms of data collection per unit time.

In contrast to the current GOES, the ABI imagery is remapped to a Fixed Grid Format before data distribution, allowing for consistency of the relationship between the pixel location and the geo-referencing, and for keeping the amount of data transmitted manageable. The ABI scans multiple sectors, including a unique target area, herein referred to as a mesoscale sector, of approximately $1000 \mathrm{~km}$ by $1000 \mathrm{~km}$ every $30 \mathrm{~s}$, or alternating mesoscale sectors every $1 \mathrm{~min}$. Many operational uses of rapid scan imagery have been demonstrated with similar one-min GOES-14 imagery, including applications for severe thunderstorm and fire events (Schmit et al. 2013; Schmit et al. 2014; Mecikalski et al. 2015; Apke et al. 2016; Line et al. 2016; Lindley et al. 2016). GOES-16 continues the critical continuity mission of GOES (Schmit et al. 2005; Kalluri et al. 2015; Greenwald et al. 2015; Gravelle et al. 2016; Goodman et al. 2017).

Figure 1 shows all 16 of the ABI bands at 1942 UTC 22 December 2017; reflectance factor is shown for the first 6 bands, with brightness temperatures (BTs) shown for bands 7 through 16 . The same BT value-color mapping is applied for the IR bands, with the exception of the three midlevel water vapor bands that have their own value-color mapping. This was done to better show water vapor gradients within the images. A similar BT image can be seen for the IR longwave windows (bands $11,13,14$, and 15), where the ABI band $7(3.9 \mu \mathrm{m})$ is warmer than the longwave windows due to reflected

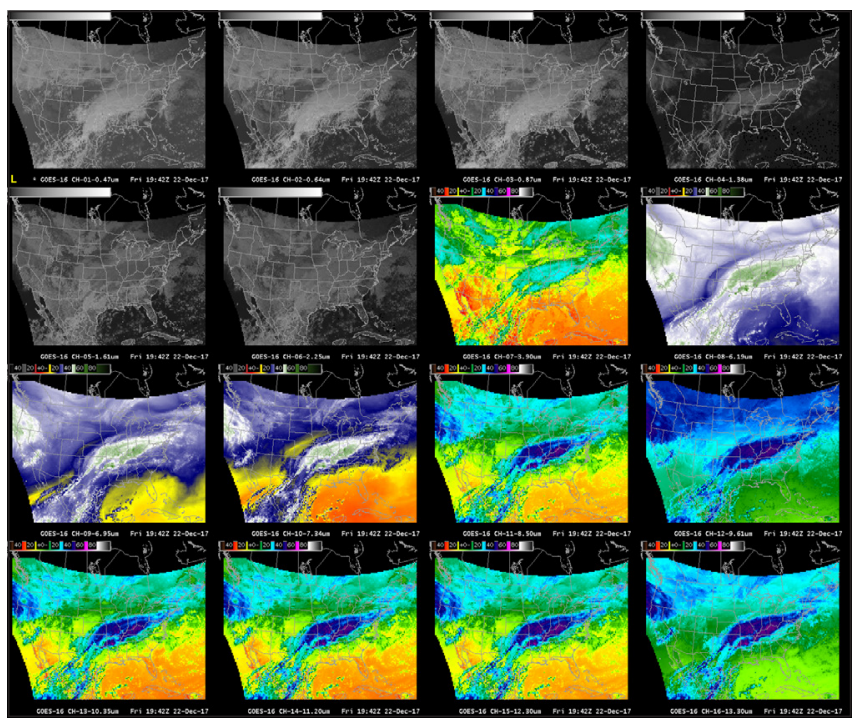

Figure 1. The 16 spectral bands of the ABI are shown as a 16-panel in the Advanced Weather Interactive Processing System (AWIPS). The first two bands sense in the visible, the following four in the near-infrared, and the final ten in the infrared. The CONUS sector image is from 1942 UTC 22 December 2017. The range for the visible and NIR bands are from approximately 0 (black) to 1.2 (white) for reflectance factors and employ a square-root function to brighten the darker parts of the image. Click image for an external version; this applies to all tables hereafter. 
Table 1. The approximate central wavelength $(\mu \mathrm{m})$, sequential band number, band type, nickname, and best spatial resolution $(\mathrm{km})$ (the ground sampling distance at the satellite subpoint) are shown for the 16 spectral bands on the ABI.

\begin{tabular}{|c|c|c|c|c|}
\hline Central Wavelength & Band & Type & Nickname & Best Spatial Resolution \\
\hline 0.47 & 1 & Visible & Red & 1 \\
\hline 0.64 & 2 & Visible & Veggie & 0.5 \\
\hline 0.86 & 3 & Near-Infrared & Cirrus & 1 \\
\hline 1.37 & 4 & Near-Infrared & Snow/Ice & 1 \\
\hline 1.6 & 5 & Near-Infrared & Cloud Particle Size & 2 \\
\hline 2.2 & 6 & Near-Infrared & Shortwave Window & 2 \\
\hline 3.9 & 7 & Infrared & Upper-level Water Vapor & 2 \\
\hline 6.2 & 8 & Infrared & Midlevel Water Vapor & 2 \\
\hline 6.9 & 9 & Infrared & Lower-level Water Vapor & \\
\hline 7.3 & 10 & Infrared & Cloud-Top Phase & 2 \\
\hline 8.4 & 11 & Infrared & Ozone & 2 \\
\hline 9.6 & 12 & Infrared & "Clean" Longwave Window & 2 \\
\hline 10.3 & 13 & Infrared & Longwave Window & 2 \\
\hline 11.2 & 14 & Infrared & "Dirty" Longwave Window & 2 \\
\hline 12.3 & 15 & Infrared & CO 2 Longwave & 2 \\
\hline 13.3 & 16 & Infrared & & 2 \\
\hline
\end{tabular}

solar energy for this daytime image. The progressively warmer BTs in the clear skies are evident in the three midlevel water vapor bands $(8,9$, and 10$)$. ABI bands 12 $(9.6 \mu \mathrm{m})$ and $16(13.3 \mu \mathrm{m})$ are cooler than the window bands in clear skies due to absorption of ozone $\left(\mathrm{O}_{3}\right)$ and carbon dioxide $\left(\mathrm{CO}_{2}\right)$, respectively. The nominal image times reflect the approximate start times. A CONUS image is subsequently captured incrementally over a period of about three min, with a full disk (in the "flex mode") captured over about $12 \mathrm{~min}$. The appearances of features within the image vary spectrally.

Table 1 lists important attributes of the ABI spectral bands, including the approximate central wavelength $(\mu \mathrm{m})$, the sequential band number, band type, nickname, and best spatial resolution (i.e., the ground sampling distance at the satellite subpoint). Figure 2 demonstrates spectrally where each of the ABI bands collects energy. These are the areas under the curves. For the two visible bands they are black outlines, whereas for all other spectral bands they are shaded in lightblue. For reference, a high spectral resolution atmospheric transmittance plot is included over the visible and NIR curves that depicts the spectral bands that are atmospheric windows (most all the visible and NIR bands) and which band is not (the "cirrus" band). A high spectral resolution IR Earth-emitted spectrum, indicative of how a clear-sky column radiates to space for small incremental changes in the IR wavelength, is included over the IR curves. This demonstrates the temperatures integrated into the brightness temperatures for each ABI spectral band when sensing the Earth. Each ABI spectral band has been assigned a nickname to ease communication and operational reference. This nickname might allude to only one of several operational applications, however. Many bands have several uses or a novel application in combination with others. Although some bands are ideal for providing imagery to the analyst, others have a primary use as input to a derived science product. For example, the $2.2 \mu \mathrm{m}$ on the ABI is used to derive cloud particle size, whereas the $13.3 \mu \mathrm{m}$ band is used to derive cloud heights.

The subsequent single-band examples shown are mostly from a satellite perspective. The operational use of the ABI bands will also include spectral differences and band combinations such as Red-Green-Blue (RBG) composites and derived products. Most significantly, in the operational setting, ABI data will be combined with other data sources, such as surface observations, radars, radiosondes and other sources. When analyzing on the finest scales, with radar data or polar-orbiting satellite imagery, for example, parallax shifts must be considered to assure the comparison of like features, though they may appear spatially offset in the imagery away from the satellite subpoint.

\section{Visible and near-infrared bands}

Operational meteorologists are familiar with the many applications of the visible band, which captures reflected sunlight off clouds and land. There is a single visible band on the legacy GOES imager, but there are six total visible and NIR bands on the ABI, including a second visible band. The NIR bands and visible bands are all reflective bands mainly limited to daytime use, so 
some users may find it more intuitive to refer to the NIR bands as "near-visible" bands because the nighttime applications are limited. This section will describe each of these six bands and their unique applications.

The $0.47 \mu \mathrm{m}$, or "Blue" visible band, is one of two visible bands on the $\mathrm{ABI}$, with imagery that is operationally useful, particularly for monitoring aerosols. This is a new band that is not on the legacy GOES imager. A band with this central wavelength is also present on the Himawari-8/9 AHI, Moderate Resolution Imaging Spectroradiometer (MODIS), and the Suomi National Polar-orbiting Partnership (NPP) Visible Infrared Imager Radiometer Suite (VIIRS) instruments. The $0.47 \mu \mathrm{m}$ band provides daytime observations of dust, haze, smoke, and clouds. Analysts will find that imagery from this "blue" visible band is hazier than from the traditional visible band. The 0.47 $\mu \mathrm{m}$ band is more sensitive to aerosols because that wavelength is in a part of the electromagnetic spectrum where clear-sky atmospheric Rayleigh scattering is more prevalent. Smoke and dust signals in this band are more apparent when the sun is low in the sky, such as sunrise and sunset, because smoke and dust are more effective at forward scattering than backward scattering (Yung 2003). There is decreased transmittance (increased scattering) at shorter visible wavelengths (Fig. 2). This is important because thin filaments of smoke, particularly small aerosols, as shown in Fig. 3, might not be detectable from longer wavelength bands.

The traditional visible band is the "Red" band at $0.64 \mu \mathrm{m}$. It has the finest spatial resolution $(0.5 \mathrm{~km}$ at the satellite subpoint) of all ABI bands. Figure 3 shows an example over Mexico with smoke that is apparent in the "Blue" band, but not as apparent in the "Red" band. Surface features are distinct in the "Red" band because of better spatial resolution and reduced Rayleigh scattering. Clouds and thick dust look similar in both visible bands. Beyond aerosols, the visible bands have a multitude of applications. The bands are ideal to identify small-scale features such as river fog, fog edges, overshooting tops, or cumulus clouds during the day. Imagery from the ABI can also be used to monitor the extent of the towering cumulus, or the existence of an orphan anvil, for clues associated with the strength of a capping inversion (Line et al. 2016). Because of the clarity of the image, the $0.64 \mu \mathrm{m}$ band also has been used during the day to monitor snow and ice cover, diagnose low-level cloud-drift winds, assist with detecting volcanic ash, and analyze hurricanes and winter storms. The $0.64 \mu \mathrm{m}$ band has been present on GOES since the mid-1970s; as such, this band extends the historical collection of imagery at this wavelength. With a slight dependence on the vegetative characteristics, land absorbs energy at $0.64 \mu \mathrm{m}$; at longer NIR wavelengths, more energy is reflected. Thus, contrast between land and reflective clouds is greater over land in the "Red" visible band than in the "Veggie" $(0.86 \mu \mathrm{m})$ or "Snow/ Ice" $(1.61 \mu \mathrm{m})$ bands. Over the open ocean, water surfaces are slightly more reflective in the $0.64 \mu \mathrm{m}$ band than in the $0.86 \mu \mathrm{m}$ band. Consequently, for monitoring maritime clouds over water, the "Veggie" band may be a better alternative to either of the visible bands.

Over land, the $0.86 \mu \mathrm{m}$ band is highly sensitive to vegetation and detects daytime clouds, fog, and some aerosols. Vegetated land, in general, appears more reflective (i.e., brighter) in this band than in visible bands. This can make it more challenging for the analyst to discern between small or thin clouds or aerosols and the underlying land surface. This band has the nickname "Veggie" because it is sensitive to changes in vegetation. It is also used to compute the normalized difference vegetation index (NDVI), an indicator of the health of the vegetation (Tucker 1979). The $0.86 \mu \mathrm{m}$ band detects energy in a part of the electromagnetic spectrum where grass is more reflective than dirt, as shown in

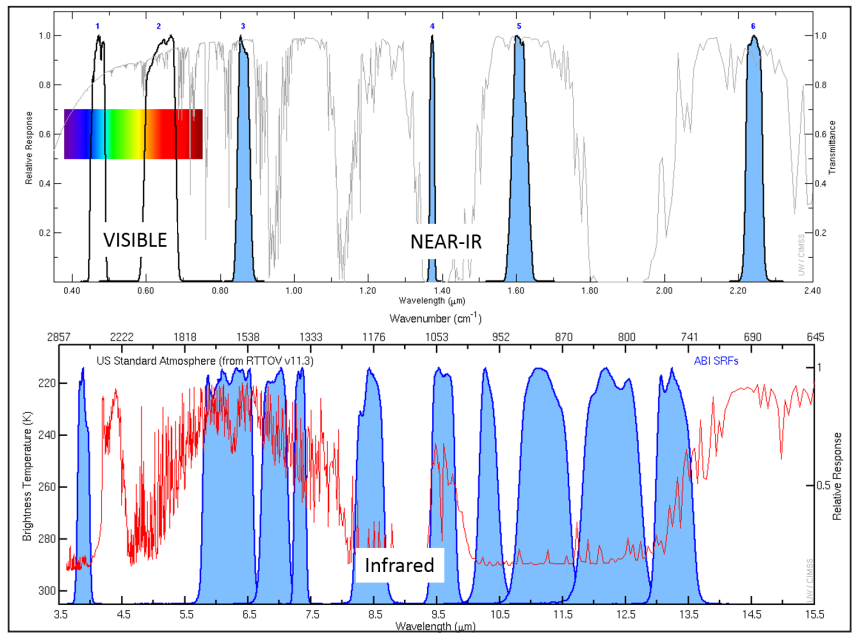

Figure 2. Plots of spectral response functions (SRFs) for the $16 \mathrm{ABI}$ spectral bands, including two visible, four near-IR, and the ten IR bands, are shown. The top panel also has a high spectral resolution atmospheric transmittance plot (in gray), whereas the bottom panel has a high spectral resolution infrared Earth-emitted spectrum (in red). Temperature decreases as the ordinate increases in the bottom panel. The abscissa shows increasing wavelength, and for the IR bands the decreasing wavenumber. 


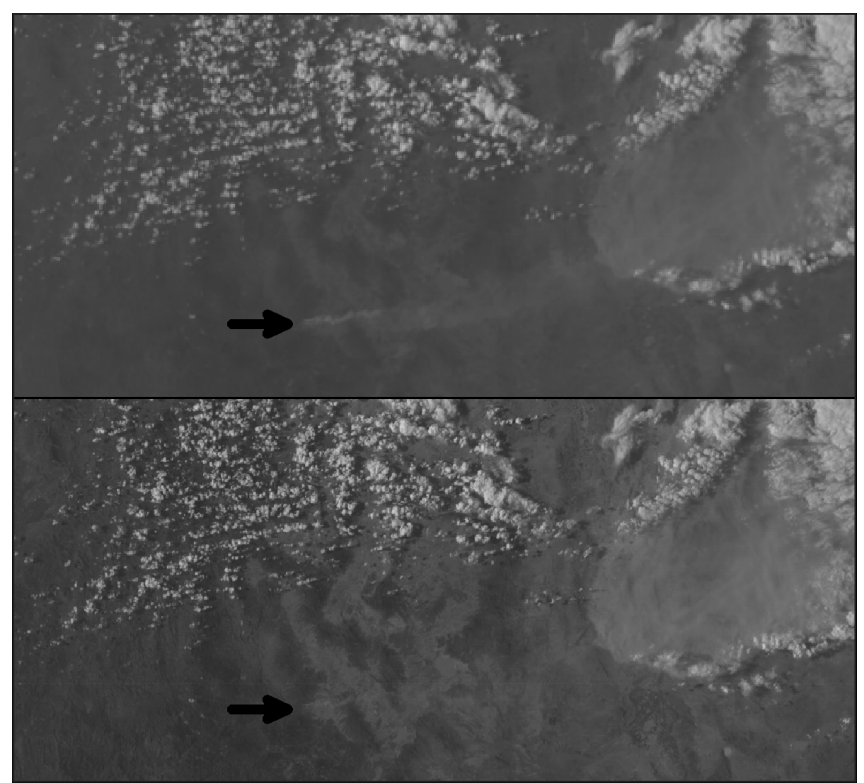

Figure 3. The "Blue" and "Red" visible bands, centered at 0.47 and $0.64 \mu \mathrm{m}$, are shown in the top panel and bottom panel, respectively. The imagery, depicting Mexico, was observed at 2247 UTC 28 March 2017. The smoke plume evident in the in the $0.47 \mu \mathrm{m}$ band (center bottom part of each panel and noted by black arrows) is not as discernable in the $0.64 \mu \mathrm{m}$ band. Both images employ a square-root function enhancement across the same range of reflectance factor values.

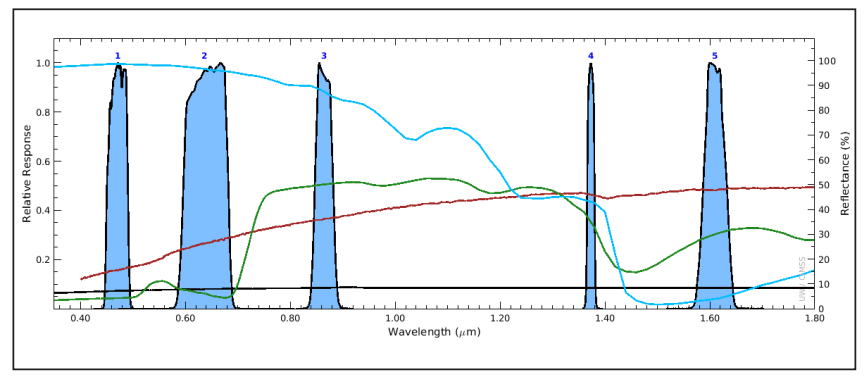

Figure 4. The visible and near-infrared spectral bands, shown in blue solid shaded areas, are underneath plotted reflectance spectra for snow (blue), grass (green), dirt (red), and asphalt (black). This plot explains why snow is bright in the visible bands, but dark in the "Snow/ Ice" band at $1.6 \mu \mathrm{m}$. Reflectance spectra are from the Advanced Spaceborne Thermal Emission Reflection Radiometer (ASTER) spectral library.

Fig. 4 (compare the green and red lines; Baldridge et al. 2014). Burn scars are also discernible in the "Veggie" band because of the reflectance contrast with vegetated land, as shown in Fig. 5. Knowledge of where burn scars exist aids in determining how a fire may spread or rainwater run-off potential. Land is more reflective at $0.86 \mu \mathrm{m}$ than in the visible bands, thus this band is useful for locating islands, lakes, flooded regions, and coastlines because of the better land-water contrast. Finally, this band is essential to simulate a "green" band that is needed for a natural color image from the ABI. All composite images can be categorized as either a true or false color image. Although an absolute true color image cannot be rendered (Liew 2001). From the ABI, we generate natural color imagery that is more intuitive (white clouds, gray smoke, blue water, etc.) than false color imagery, which requires users to have advanced training to properly interpret (e.g., clouds could be displayed as pink or blue). Through the use of a modified "Veggie" band as a substitute to complement the red and blue visible bands, true natural color imagery can be created, even though a green visible band does not exist on ABI (Miller et al. 2012; Miller et al. 2016). ABI's counterpart, the AHI that flies on Himawari-8/9, does have a green visible band centered at $0.51 \mu \mathrm{m}$ (Bessho et al. 2016).

Himawari-8/9 AHI does not have the "Cirrus" band that, at $1.37 \mu \mathrm{m}$, is unique among the reflective bands on the ABI. The "Cirrus" band occupies a section in

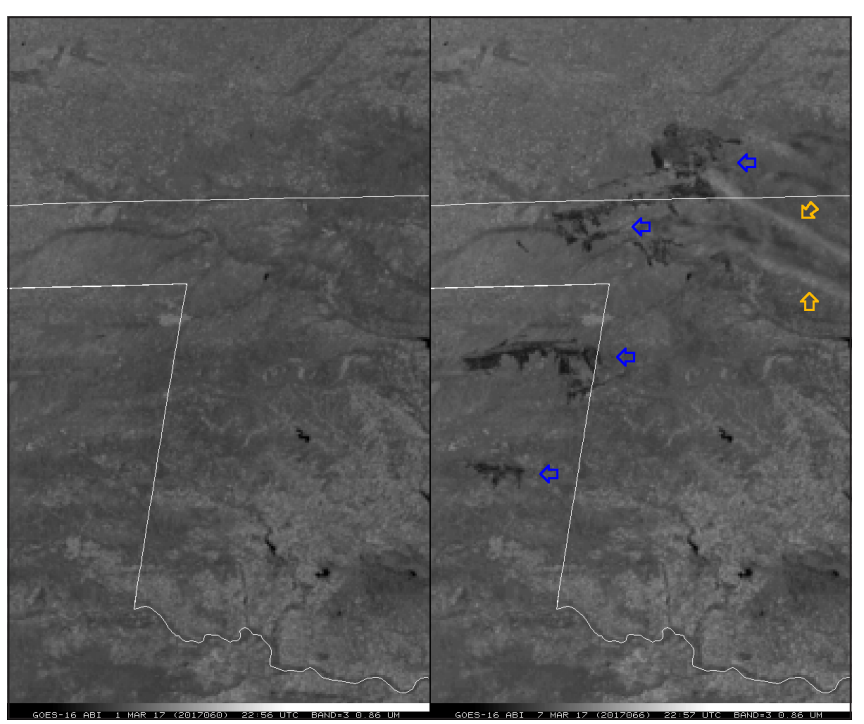

Figure 5. The $0.86 \mu \mathrm{m}$ "Veggie" band at 2300 UTC 1 March 2017 (left) and 7 March 2017 (right) over the Texas /Oklahoma panhandle. A number of burn scars are seen as darker regions in the image from 7 March 2017 and are highlighted with blue arrows. Bodies of water also appear dark. Smoke from active fires is also evident in Kansas and Oklahoma and highlighted with a set of orange arrows. The McIDAS-X default squareroot enhancement was used on both images. 
the electromagnetic spectrum of strong water vapor absorption. The spectral response function (SRF) for the "Cirrus" band, coupled with the transmittance as in Fig. 2, demonstrates the strong absorption by water vapor in this spectral region. As with the water vapor bands in the IR, energy at $1.37 \mu \mathrm{m}$ is absorbed by water vapor as that energy moves through the troposphere. This band can sense very thin cirrus clouds during the day, as shown in Fig. 6, and contrails. Clouds at low levels are also evident in this band if the atmosphere is suitably dry. This band may detect highly reflective features, such as dust, or clouds, if there is limited water vapor above them, though their reflectance will likely be less than in the visible or "Veggie" bands. Theory suggests that approximately 0.5 in $(12 \mathrm{~mm})$ of total precipitable water (TPW) is sufficient to absorb most of the solar radiation at $1.37 \mu \mathrm{m}$ (Sieglaff and Schmit 2003). Variable amounts of moisture and its vertical distribution influence how close to the surface the satellite can observe features at this wavelength. Therefore, cirrus clouds are readily depicted whereas low clouds are not detected in a moist atmosphere. In contrast, coastlines and other land features can be evident in dry regions. Animations of $1.37 \mu \mathrm{m}$ imagery can help discern meteorological features from stationary land features.

The spectral range of the "Snow/Ice" band around $1.61 \mu \mathrm{m}$ takes advantage of the difference between the refraction components of water and ice that controls the

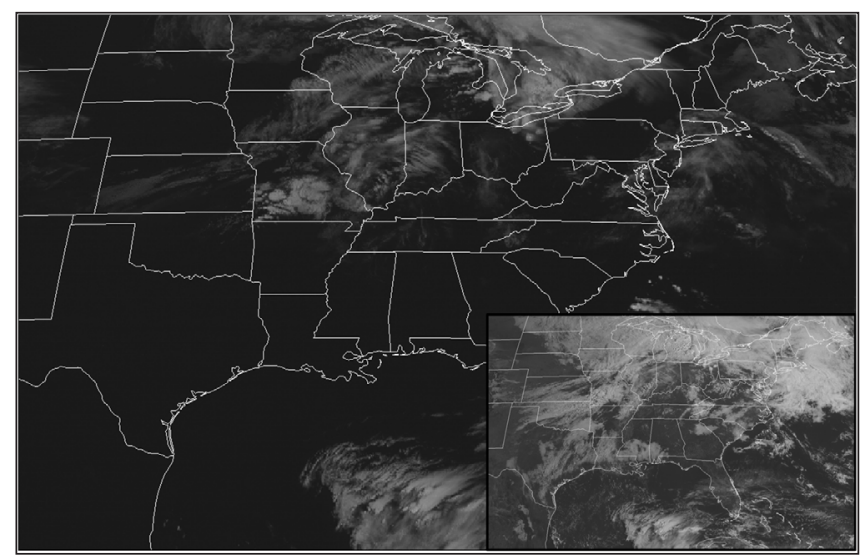

Figure 6. The main panel is the $1.37 \mu \mathrm{m}$ "Cirrus" band, whereas the bottom-right insert is the $0.64 \mu \mathrm{m}$ "Red" visible band. Both images are from 1337 UTC 20 April 2017. The high clouds in the $1.37 \mu \mathrm{m}$ band over Kansas are evident whereas the low clouds in Texas are not. Several small-scale clouds are seen off the southern coast of North Carolina, but those clouds are not distinguishable as high clouds in the $0.64 \mu \mathrm{m}$ band. reflectance of clouds depending on their composition. Liquid water clouds are highly reflective and therefore bright in this band whereas ice clouds and snow are darker because ice absorbs, rather than reflects, radiation around $1.61 \mu \mathrm{m}$. Thus, the analyst can infer phase of the cloud top: cirrus will be darker, compared to more reflective, and therefore lighter, water-based cumulus and stratus clouds. An example of varying cloud reflectance in the $1.61 \mu \mathrm{m}$ band is shown in Fig. 7. The associated animation demonstrates how the differential horizontal and vertical motions of clouds of different reflectance can help in discerning cloud layers and when a cloud has glaciated. During the day, analysts can compare the $1.61 \mu \mathrm{m}$ band with the visible $0.64 \mu \mathrm{m}$ band not only to easily discern reflective water clouds from ice clouds, but also to determine fires in cloudfree areas and discern surface ice accumulations from snow accumulations. Land-water contrast is strong at $1.61 \mu \mathrm{m}$ and shadows can be particularly striking because there is less atmospheric scattering in the NIR. Scattering would otherwise lessen the evidence of shadows. Although the $3.9 \mu \mathrm{m}$ band is most useful for detecting hot spots, at night, fires or gas flares may be evident to the analyst using the $1.61 \mu \mathrm{m}$ band owing to the favorable Planck function for hot sources of emission relative to this wavelength. This is especially

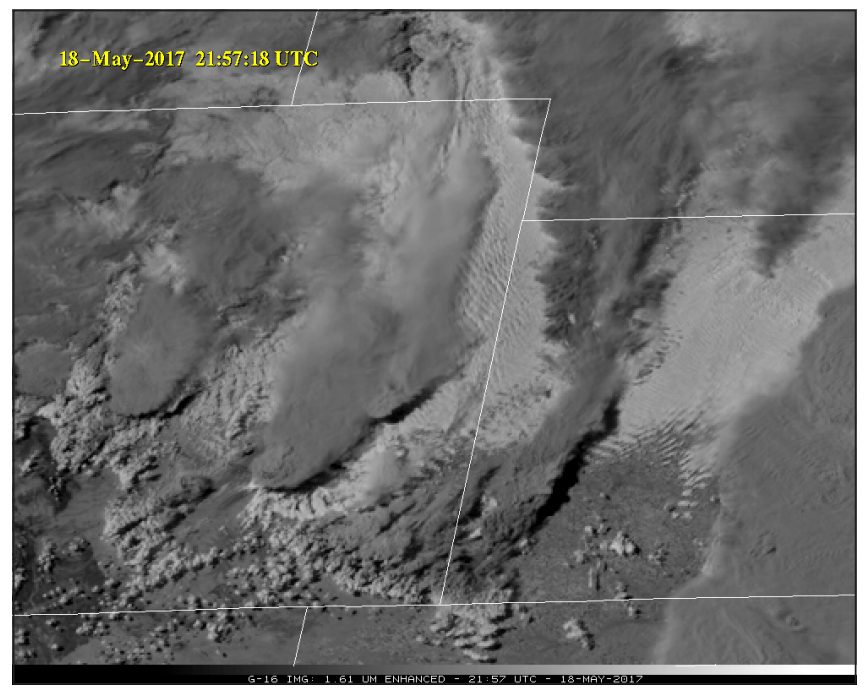

Figure 7. The $1.61 \mu \mathrm{m}$ "Snow/Ice" band at 2157 UTC 18 May 2017 reveals darker (less reflective) clouds that have glaciated interspersed with the brighter (more reflective) water cloud. The minimum and maximum reflectance factor values are 0 and 1 , respectively, using the square-root function. Dark shadows to the east of some glaciated clouds can also be seen. Click image for animation. 
true of particularly hot features, but monitoring clouds using other bands is necessary because cloud motion or development can obscure the nighttime view of a fire.

Most fires evident in the $1.61 \mu \mathrm{m}$ band are also evident in the $2.2 \mu \mathrm{m}$ band. The "Cloud Particle Size" band can also be used to determine cloud phase derived product, but the band's coarser resolution means analysts should use the "Snow/Ice" band instead, especially because there is less contrast between frozen and liquid water than in the $2.2 \mu \mathrm{m}$ band. The $2.2 \mu \mathrm{m}$ band is used in a number of RGB, such as the Fire Temperature and Day Land Cloud Fire images.

\section{Infrared bands}

There are only four IR bands on the legacy GOES imager; in contrast, there are ten IR bands on the ABI, though most operational users will not need to routinely evaluate each of the ten. The ten IR bands include three midlevel water vapor bands, five atmospheric window bands, and unique " $\mathrm{O}_{3}$ " and " $\mathrm{CO}_{2}$ " bands. As with the visible and NIR bands, the IR ABI bands also have improved spatial and temporal resolution, and improved calibration. All of the IR bands have a spatial resolution of $2 \mathrm{~km}$ at the satellite subpoint.

The $3.9 \mu \mathrm{m}$ "Shortwave IR" band, following in the legacy from the current GOES imager, is special among ABI bands because it routinely senses both Earthemitted terrestrial IR radiation as well as reflected solar radiation during the day, which is evident from comparing the $3.9 \mu \mathrm{m}$ band image to the $10.3 \mu \mathrm{m}$ band image in Fig. 1. Fire detection, per Fig. 8, is the most well-known use of this band because its shorter wavelength is more sensitive to temperature than longer wavelength IR bands. The animation associated with Fig. 8 shows how the $3.9 \mu \mathrm{m}$ band is more sensitive to temperature than the $10.3 \mu \mathrm{m}$ band. During the night, the land temperatures are similar, but during the day the $3.9 \mu \mathrm{m}$ band includes solar reflections. The shortwave window band can also be used to identify fog and low clouds at night, locate urban heat islands, detect volcanic ash, estimate surface temperatures, distinguish between airmasses, and discriminate between ice crystal sizes during the day. During the day, water clouds and high clouds with very small ice crystals reflect $3.9 \mu \mathrm{m}$ solar radiation effectively and therefore show a warm BT in the $3.9 \mu \mathrm{m}$ band imagery; small ice crystals also reflect $3.9 \mu \mathrm{m}$ solar radiation, but not as effectively, and hence do not show such a warm BT. Large ice crystals do not reflect $3.9 \mu \mathrm{m}$ solar radiation well, and hence

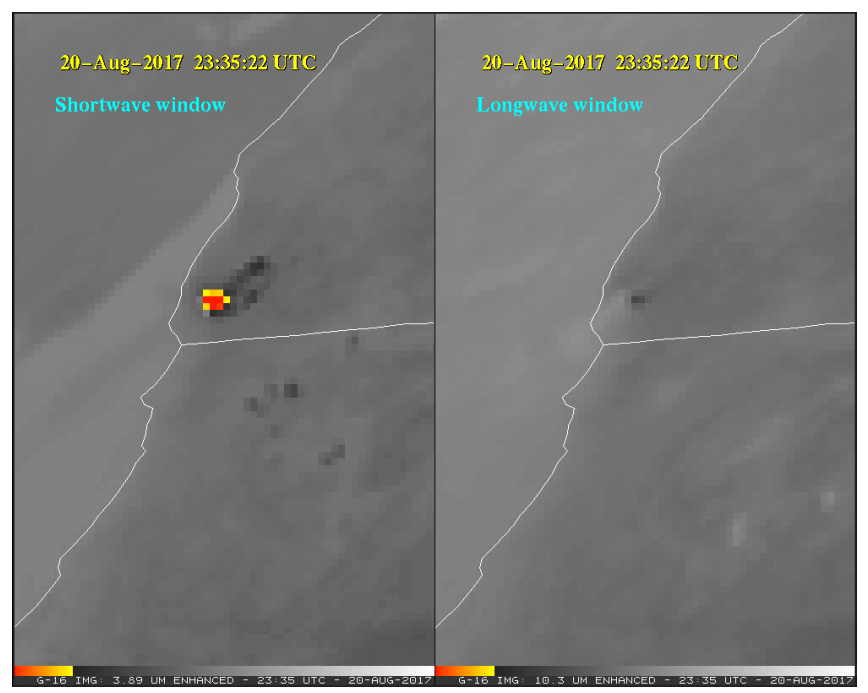

Figure 8. A wildfire is shown in two IR bands: the $3.9 \mu \mathrm{m}$ "Shortwave" band and the $10.3 \mu \mathrm{m}$ "Clean Longwave Window" band, at 2335 UTC 20 August 2017 along the coast of California and Oregon. Hotter pixels are colored yellow $(363 \mathrm{~K})$ to red $(400 \mathrm{~K})$; the coldest pixels are a light shade of gray (down to $200 \mathrm{~K}$ ). Fires are more evident in the $3.9 \mu \mathrm{m}$ band, compared to the $10.3 \mu \mathrm{m}$. band. Click image for animation.

show colder BTs. The need to sense both hot fires and distinguish features of cold cloud tops requires that the $\mathrm{ABI}$ have the capability to capture a broader range of potential BTs and maintain a reasonable precision at $3.9 \mu \mathrm{m}$. For this reason, the $3.9 \mu \mathrm{m}$ band imagery is 14 bits, allowing for $2^{14}$ or 16,384 discrete values, from the maximum value of $411 \mathrm{~K}$, or $138^{\circ} \mathrm{C}$. This range is much greater than the current GOES imager provides.

The ABI has an "Upper-Level Water Vapor" band centered at $6.2 \mu \mathrm{m}$. It is one of three midlevel water vapor bands on the ABI, and is used for tracking uppertropospheric winds, identifying jet streams, forecasting hurricane track and mid-latitude storm motion, monitoring severe weather potential, estimating upper and midlevel moisture, and identifying regions where the potential for turbulence exists. Figure 9 demonstrates the utility of the "Upper-level Water Vapor" band in characterizing synoptic features, showing an upperlevel trough over the Upper Midwest with a dry slot along eastern Arkansas, polar jet stream axis over Louisiana and Mississippi, and the subtropical jet steam axis over central Florida. In Fig. 9, there is diffluent flow aloft between the subtropical and polar jets, implying upward vertical motion supportive of convection (thunderstorms). Further, these water vapor bands can be used to validate numerical weather prediction model 


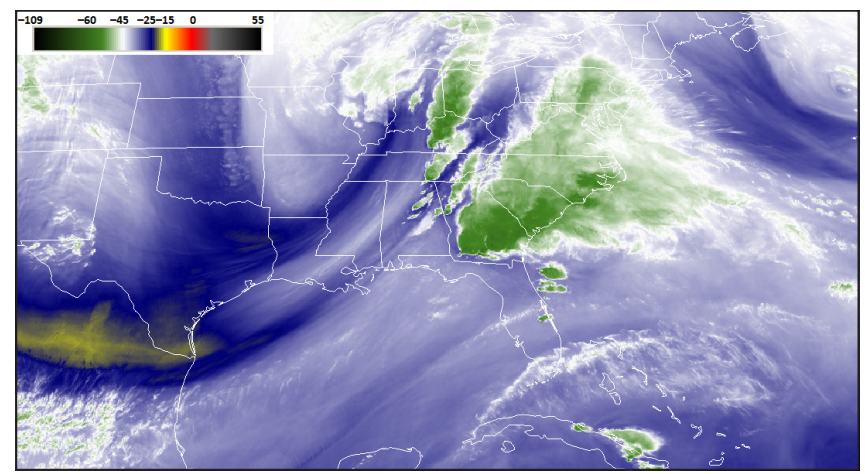

Figure 9. The image of the $6.2 \mu \mathrm{m}$ "Upper-Level Water Vapor" band at 2047 UTC 5 April 2017 depicts a diffluent region on the front side of a mid-latitude trough. White and green shades represent colder brightness temperatures than the navy and yellow shades.

initialization or be directly assimilated. Warming or cooling with time can reveal vertical motions at midand upper levels. The "water vapor" bands are IR bands that sense the mean temperature of a variabledepth layer of moisture - a layer whose altitude and depth can vary, depending on both the temperature and moisture profile of the atmospheric column, as well as the satellite viewing angle.

The $6.9 \mu \mathrm{m}$ "Midlevel Water Vapor" band is the second of three midlevel water vapor bands on the ABI, and although generally contains warmer BTs than the band centered at $6.2 \mu \mathrm{m}$, has many of the same potential applications as the other two bands. The "midlevel" that this band senses will depend on the atmosphere; in some tropical airmasses the "Midlevel Water Vapor" band may sense temperatures characteristic of the environment at pressures lower (higher heights) than $500 \mathrm{hPa}$. In other dry or cold atmospheres, the satellite may sense at pressures higher (lower heights) than 500 $\mathrm{hPa}$. Mountain waves might be more evident in this band than in the other water vapor bands, depending on the topography as well as the atmospheric temperature and moisture profile, but surface features are usually not apparent in this band. For all applications, it is best to maintain the full bit depth of the ABI in the display system (Wimmers et al. 2018) because some features, such as gravity waves, may only differ from the background by a few tenths of a degree Celsius.

Warmer yet than the other two water vapor bands is the $7.3 \mu \mathrm{m}$ "Lower-level Water Vapor" band. Along with the applications for the other two water vapor bands, additional applications include tracking the elevated mixed layer to determine atmospheric destabilization, highlighting volcanic plumes that are rich in sulfur dioxide $\left(\mathrm{SO}_{2}\right)$, and tracking lake-effect snow bands. In cloud-free regions, this water vapor band senses molecules farthest down in to the atmosphere, as shown in the leftmost panel of Fig. 10. Mountaintops are sometimes apparent in this spectral band, and in particularly dry winter atmospheres, coastlines and shorelines such as around the Great Lakes may become partially evident. In addition, subtracting the $7.3 \mu \mathrm{m}$ band BT from the $6.2 \mu \mathrm{m}$ band BT can provide evidence of stratospheric intrusions, because the $6.2 \mu \mathrm{m}$ band has some contribution from that height.

Examination of water vapor weighting function plots (Schmit et al. 2017) can help in the correct interpretation of the three-dimensional aspects of patterns displayed on water vapor imagery. Weighting functions depict the layer of the atmosphere from which the satellite-sensed radiation originated. Weighting function computations typically assume a cloud-free sky can be computed with a US standard atmosphere profile or observed sounding. Weighting functions for most IR bands depend on the water vapor distribution, but the "Upper-level Water Vapor" band generally has the highest peak in altitude (lowest pressure) of the three ABI water vapor bands. BTs of all three IR water vapor bands cool as the satellite viewing angle increases away from the satellite subpoint. For pixels away from the satellite subpoint, the path of energy from Earth to the satellite includes more of the cooler upper troposphere. This increase in satellite viewing angle is due to an increase of latitude or change in longitude away from the satellite subpoint for satellites in geostationary orbit. For identical tropospheric conditions observed at a different angle, the BT might be $8 \mathrm{~K}$ cooler at the limb

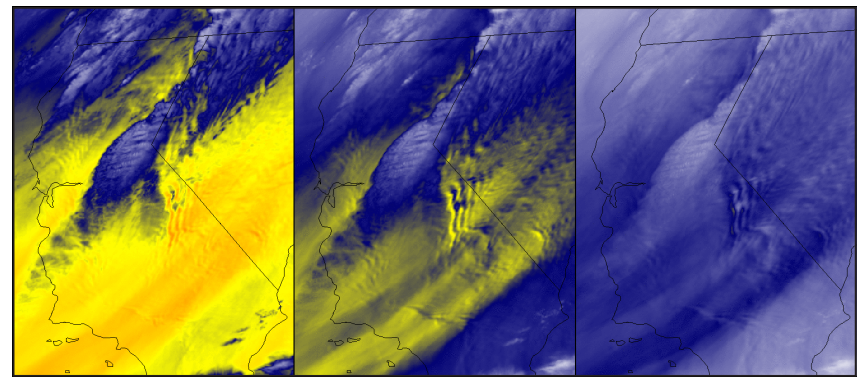

Figure 10. The three water vapor $\mathrm{ABI}$ bands $(7.3,6.9$, and $6.2 \mu \mathrm{m}$, from the leftmost panel to the rightmost panel, respectively) at 1202 UTC 13 April 2017 depict mountain waves downwind of the Coastal Ranges and the Sierra Nevada. Yellow and orange colors depict warmer brightness temperatures than blue and white shades. The same temperature scale was used as in Fig. 9. 
versus at nadir.

BTs at other wavelengths show cooling because of other trace gases, in a manner similar to the cooling due to water vapor absorption in the other IR bands. In particular, the " $\mathrm{O}_{3}$ " Band, at $9.6 \mu \mathrm{m}$, and the " $\mathrm{CO}_{2}$ " band, at $13.3 \mu \mathrm{m}$, are subject to absorption due to $\mathrm{O}_{3}$ and $\mathrm{CO}_{2}$, respectively, in addition to water vapor. The $9.6 \mu \mathrm{m}$ band can provide information both day and night about the dynamics of the atmosphere near the tropopause, for example the identification of upper jet streaks. This band shows cooler BTs in clear skies than the clean IR window band because both $\mathrm{O}_{3}$ and water vapor absorb and re-emit energy to space at 9.6 $\mu \mathrm{m}$. The cooling effect is especially apparent at large zenith angles. In contrast, the tops of deep convective clouds at the tropopause are warmer in the " $\mathrm{O}_{3}$ " band than in other bands because of $\mathrm{O}_{3}$ absorption and reemission at warmer temperatures in the stratosphere. This band cannot detect concentrations of near-surface $\mathrm{O}_{3}$, nor can it alone diagnose total column $\mathrm{O}_{3}$. The creation of science products using additional bands is necessary for that. Furthermore, water vapor absorption occurs in this band, complicating the direct use of the $9.6 \mu \mathrm{m}$ band because the horizontal distribution of $\mathrm{O}_{3}$ and water vapor varies across the globe. BTs will generally increase as water vapor and/or $\mathrm{O}_{3}$ decreases within a column, or as air temperatures increase in the layer where the concentration of water vapor or $\mathrm{O}_{3}$ is maintained. See cimss.ssec.wisc.edu/goes/wf to experiment with how the BTs and weighting functions are sensitive to varying moisture, temperature, viewing angle, etc. for theoretical atmospheres.

Although the three water vapor bands are known for depicting the distribution of water vapor, almost all IR bands are at least slightly influenced by water vapor. In many cases, this influence is reflected in a slightly cooler BT than would otherwise have been observed. The $10.3 \mu \mathrm{m}$ "Clean Longwave Window" band is least sensitive than other IR window bands to water vapor absorption and therefore improves atmospheric moisture corrections, cloud and other atmospheric feature identification and classification, estimates of cloudtop temperature and cloud particle size, and surface property characterization in derived products (Lindsey et al. 2012). Analysts conducting a Dvorak analysis of a tropical cyclone apply the "BD" (Base Dvorak) curve to the $10.3 \mu \mathrm{m}$ band (Dvorak 1984). In clear sky, the $10.3 \mu \mathrm{m}$ BTs are not necessarily representative of 2 $\mathrm{m}$ shelter air temperatures because the land can warm substantially compared to the near-surface air during the day. At night, strong radiational cooling can result in cooler land temperatures than shelter temperatures. The satellite-measured IR BTs do not provide a truly accurate skin temperature since there is some absorption of upwelling energy by atmospheric water vapor from the lower troposphere. There is a baseline product for land surface temperature (Schmit et al. 2017) that can provide a better estimate than imagery.

Beyond surface properties, the $10.3 \mu \mathrm{m}$ band is useful for monitoring thunderstorm growth and movement. Figure 11a shows cloud-top storm structure, which features an enhanced-V signature, colored in red, with overshooting tops in black to white, plus the thermal couplet that contrasts cold cloud from the adjacent warm region in yellow and green. The enhanced-V and thermal couplet IR storm-top signatures (McCann 1983; Brunner et al. 2007) are associated with thunderstorms that are, or will be, producing damaging winds, large hail, or tornadoes within 20 to $30 \mathrm{~min}$ (Dworak et al. 2012; Bedka et al. 2015). Figure 11b is the corresponding time from the Multi-Radar MultiSensor (MRMS) composite (Smith et al. 2016). The satellite and radar can complement each other, with the radar showing the precipitation cores and downdrafts with the satellite best capturing overshooting tops above the updrafts. The apparent location of the convection is offset due to parallax. This case dates to when GOES-16 ABI was centered near $89.5^{\circ} \mathrm{W}$; the parallax shift will be greater over this region when viewed by $\mathrm{ABI}$ at $75.2^{\circ} \mathrm{W}$. The ABI can help fill in radar gaps, either permanent ones in the western United States, or temporary ones associated with radar outages. For example, one of the ABI mesoscale sectors was placed over Puerto Rico for weeks after Hurricane Maria destroyed its radar.

In comparison, the $11.2 \mu \mathrm{m}$ band is the traditional "Longwave Window"; however, there is more absorption of energy by water vapor at this wavelength compared to the aforementioned clean window. This band has similarities to the legacy IR band on current GOES at $10.7 \mu \mathrm{m}$. However, for most operational applications, it is best to use the $10.3 \mu \mathrm{m}$ band because BTs in the cleanest window will be closer to feature temperatures. BTs in the $11.2 \mu \mathrm{m}$ band will be cooler than those in the $10.3 \mu \mathrm{m}$ band for the same feature by an amount that is a function of the amount of moisture in the atmosphere. For clouds, it is possible to discern their phase by subtracting the $11.2 \mu \mathrm{m}$ band cloudy BTs from the corresponding $8.4 \mu \mathrm{m}$ "Cloud-Top Phase" band BTs. This difference is particularly valuable at night when there are no NIR bands (Strabala et al. 

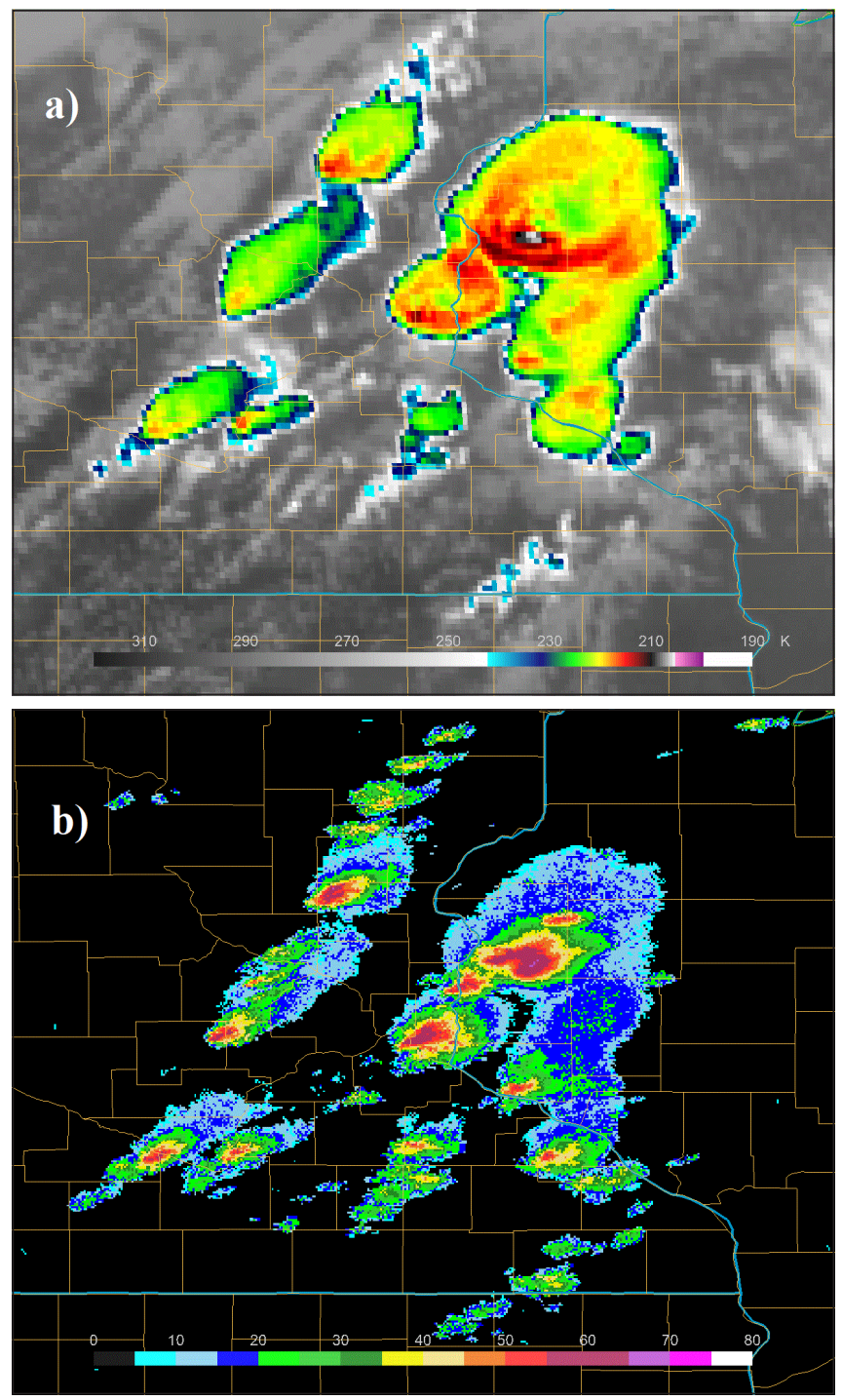

Figure 11. a) The $10.3 \mu \mathrm{m}$ "Clean IR Window" band image from 2127 UTC 16 May 2017 over Minnesota and Wisconsin depicts enhanced-V signatures (" $u$ " or " $\mathrm{v}$ " shaped signatures are depicted in yelloworange-red colors in the southwestern parts of several clouds) associated with strong thunderstorms. b) The corresponding 2128 UTC 16 May 2017 radar composite.

1994). For ice clouds, the difference between the 11.2 $\mu \mathrm{m}$ and $8.4 \mu \mathrm{m}$ will be greater than it is for water clouds because of a difference in the emissivity of ice clouds between the two bands. The emissivity of an ice cloud is lower around $11.2 \mu \mathrm{m}$ than it is at $8.4 \mu \mathrm{m}$. This produces a negative $11.2 \mu \mathrm{m}$ minus $8.4 \mu \mathrm{m}$ BT difference. Otherwise, the $11.2 \mu \mathrm{m}$ band and $12.3 \mu \mathrm{m}$ band, discussed next, when used independently, have similar applications as the $10.3 \mu \mathrm{m}$ band. Therefore, there is no reason for the analyst to consult multiple window bands in most analysis scenarios.

Absorption and re-emission of water vapor, particularly in the lower troposphere, slightly cools most cloud-free BTs in the $12.3 \mu \mathrm{m}$ "Dirty Longwave Window" band compared to the other IR window bands. Subtraction of the $12.3 \mu \mathrm{m}$ BT from the 10.3 $\mu \mathrm{m}$ BT yields the "split window difference" (SWD); a larger SWD (Lindsey et al. 2014) will reflect areas of more water vapor in cloud-free areas. More on BT band differences are covered in section 4 . The $12.3 \mu \mathrm{m}$ band is part of many baseline products, including the clear sky mask, cloud top properties, legacy atmospheric profiles, volcanic ash, and fire hot spot characterization. The nickname for this band is the "Dirty Longwave Window" precisely because water vapor cools the BTs and therefore "dirties" the image.

Unlike $\mathrm{O}_{3}, \mathrm{CO}_{2}$ is fairly homogeneous in the troposphere. The $13.3 \mu \mathrm{m}$ " $\mathrm{CO}_{2}$ " band, another legacy band from the current GOES imager and sounder (Schmit et al. 2002), is useful for science algorithms and derived products that require delineating the tropopause, estimating cloud top heights, and discerning the level of derived motion winds. Cloud information from the $13.3 \mu \mathrm{m}$ band complements the Automated Surface Observing System sky observations for high cloud, and is vital for some baseline products, such as cloud top height. Despite its importance in products, the $\mathrm{CO}_{2}$ band is typically not used for visual interpretation of weather phenomena, although the imagery from this band could be compared to a troposphere-averaged column temperature plot from a numerical weather prediction model to compare the position of any ridges in the wave train to higher temperatures. In this band, lower BTs are especially noticeable near the limb, more so than any other $\mathrm{ABI}$ band other than the " $\mathrm{O}_{3}$ " band. The Earth's surface is evident in clear skies, but strong cooling from $\mathrm{CO}_{2}$ means $13.3 \mu \mathrm{m}$ BTs are cooler than in the traditional IR window bands, except where there are clouds at the tropopause.

\section{Other uses of ABI spectral bands}

Understanding and comfortably interpreting features in individual spectral bands is an important first step for analysts to leverage the increased information content from the ABI compared to previous geostationary imagers. Analysts can also apply imagery in more advanced methods. For example, there are benefits for analysts to use band differences, RGB composites, and quantitative derived products in certain scenarios. 
Certain band differences were mentioned because some bands have comparative value with other bands.

The "split window difference" $(10.3 \mu \mathrm{m}-12.3 \mu \mathrm{m})$ is an important difference that can assist the analyst in detecting both moisture and dust. The amount and location of moisture is a key parameter associated with the development and sustenance of convection. The moisture application was discussed previously, but the split window difference can also distinguish volcanic ash and dust silicates from cloud water and ice. The emissivity of silicates is lower at $10.3 \mu \mathrm{m}$ than at 12.3 $\mu \mathrm{m}$, so $10.3 \mu \mathrm{m}$ BTs are cooler than $12.3 \mu \mathrm{m}$ BTs for dust and volcanic ash scenes. Airborne dust, including Saharan Air Layers that suppress tropical cyclogenesis, can also be detected by the difference of these two window bands.

In lieu of a band difference, an alternative to show information from two bands is to overlay them and set the top image to be semi-transparent. An example from Hurricane Irma shown in Fig. 12 uses the ABI "Red" band with a grayscale enhancement beneath the $10.3 \mu \mathrm{m}$ "Clean Longwave Window" for the corresponding time, colorized according to the BT. This method is similar in concept to the multi-spectral "sandwich" approach of Setvák et al. (2013). To visualize more than two bands in a single image, RGB composites, which may be either natural or false color, are becoming increasingly popular. False color RGB composites require special training to master whereas natural color imagery does not.

There are many false color RGBs though, some of which rely heavily on individual bands. The "Upperlevel Water Vapor" band is a key component of the air mass RGB product (Zavodsky et al. 2013), helping to highlight jet stream axes and distinguish dry $\mathrm{O}_{3}$-rich stratospheric air associated with potential vorticity anomalies and tropopause folds. Another example of a RGB composite is the "day land cloud" that is shown over the full disk in Fig. 13, which clearly shows the difference between liquid and frozen clouds. Without natural color imagery from geostationary imagers, this RGB also has been known as the natural color composite. Natural color composites can be used as a quick look for situational awareness, with respect to clouds, fog, snow, smoke, vegetation and several other phenomena. It can also be used as a dynamic background image for over-plotting other information, such as outlooks.

To complement these ABI bands, there are quantitative products that are routinely computed from individual bands. For example, the $7.3 \mu \mathrm{m}$ band data are used as input for the creation of derived motion winds, the clear sky mask, stability indices, total precipitable water, rain rates, and volcanic ash products (Pavolonis et al. 2013; Lee et al. 2014; Schmit et al. 2017). For a

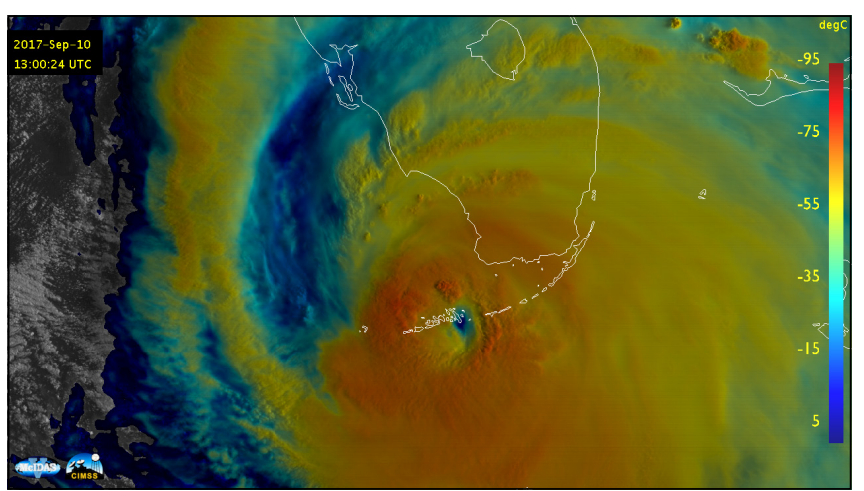

Figure 12. This animation beginning at 1300 UTC 10 September 2017 depicts the evolution of Hurricane Irma approaching Florida. This sandwich product combines the ABI "Red" band with the corresponding brightness temperatures from the "Clean Longwave Window" band. Click image for animation.

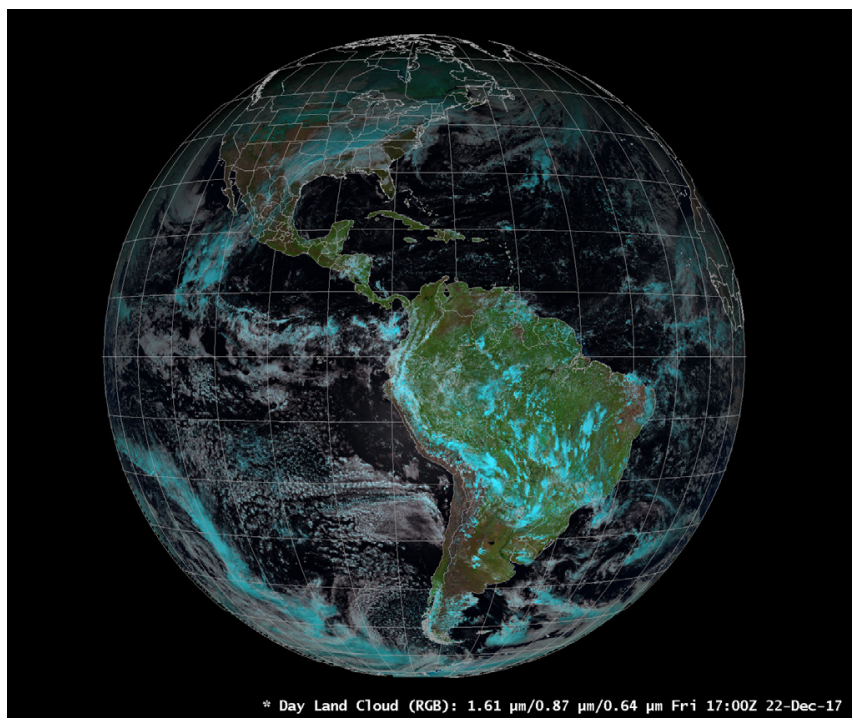

Figure 13. There are many possible spectral combinations of the ABI bands. The "day land cloud" RGB composite as displayed in the Advanced Weather Interactive Processing System (AWIPS) from 1700 UTC 22 December 2017 depicts ice clouds in cyan. This is the view from approximately $75^{\circ} \mathrm{West}$ longitude. This RGB is also known as the "natural color" by EUMETSAT (European Organization for the Exploitation of Meteorological Satellites). In this image, the vegetation band can make certain surfaces appear too green. 
comprehensive list of the $\mathrm{ABI}$ products and their band inputs, see Schmit et al. (2017).

\section{Conclusions}

The ABI on the GOES-R series, and similar advanced imagers in geostationary orbit around the world, represent a major technological leap in the field of meteorological and environmental remote sensing. GOES-16 is the first in a series of four GOES-R Series spacecraft that will provide imagery for American weather monitoring for the next two decades. The $\mathrm{ABI}$ is much improved compared to the legacy GOES imager: the ABI samples more spectral bands and has finer spatial and temporal resolutions. The coverage rate is approximately five times faster, the spatial resolutions four times finer, and the number of spectral bands approximately three times more. In addition, there is improved image navigation and registration, improved bits per pixel, improved dynamic range, and improved calibration. This cumulatively results in a minimum data quality and resolution improvement of 100 times more than the legacy GOES imager. The ABI complements a Geostationary Lightning Mapper and many space weather instruments onboard the GOES-R series (Goodman et al. 2013).

The official web site for the GOES- $R$ series mission, www.goes-r.gov, hosts $16 \mathrm{ABI}$ band fact sheets created prior to launch; an updated set of 16 band quick guides, tailored for National Weather Service (NWS) meteorologists, use post-launch GOES-16 imagery. Readers of the fact sheets and quick guides will find detailed applications for the ABI spectral bands, including: numerical weather prediction (improved forecasts), severe weather (improved lead times), hazards (volcanic ash plumes), aviation (turbulence), environmental (fires), health (smoke), oceanographic (sea surface temperature), cryosphere (snow cover), and land (burn scars).

Acknowledgments: The views, opinions, and findings contained in this report are those of the authors and should not be construed as an official National Oceanic and Atmospheric Administration or United States Government position, policy, or decision.

The authors thank everyone who helped with the ABI band fact sheets and quick guides, including the pre-launch set (Steve Goodman, Michelle Smith, Bill Ward, Carven Scott, Ken Johnson, and many others at National Oceanographic and Atmospheric
Administration (NOAA) cooperative institutes and in the GOES-R Program Office) and the post-launch set (many NWS Science and Operations Officers, the Satellite Training Group, and other training specialists). Thanks are also extended to Scott Bachmeier for the water vapor band fact sheets. Joleen Feltz provided the combined visible-infrared imagery of Hurricane Irma. All who helped make the imagery from ABI possible are also thanked.

ABI data are archived at NOAA's CLASS: www. class.noaa.gov. The ABI imagery shown in this manuscript from before 18 December 2017, was preliminary and non-operational. This manuscript used software packages designed to display imagery from GOES-R: McIDAS-X and McIDAS-V, AWIPS, and the Satellite Information Familiarization Tool (SIFT), which is available to download for free from sift.ssec. wisc.edu, to create figures. This research was supported in part by a NOAA grant to the Cooperative Institute for Meteorological Satellite Studies at the University of Wisconsin-Madison (NA15NES4320001).

Other GOES-16 cases demonstrating operational applications can be found at the CIMSS Satellite Blog: cimss.ssec.wisc.edu/goes/blog/archives/category/ goes-16. Thanks to the many groups that made the ABI possible, including from the government, private industry and academia.

\section{REFERENCES}

Apke, J. M., J. R. Mecikalski, and C. P. Jewett, 2016: Analysis of mesoscale atmospheric flows above mature deep convection using super rapid scan geostationary satellite data. J. Appl. Meteor. Climatol., 55, 1859-1887. CrossRef.

Baldridge, A. M., S. J. Hook, C. I. Grove and G. Rivera, 2009. The ASTER spectral library version 2.0. Remote Sensing of Environment, 113, 711-715. CrossRef.

Bedka K., C. Wang, R. Rogers, L. D. Carey, W. Feltz, and J. Kanak, 2015: Examining deep convective cloud evolution using total lightning, WSR-88D, and GOES14 super rapid scan datasets. Wea. Forecasting, 30, 571590. CrossRef.

Bessho, K., and Coauthors, 2016: An introduction to Himawari-8/9-Japan's new-generation geostationary meteorological satellites. J. Meteor. Soc. Japan, 94, 151183. CrossRef.

Brunner, J. C., S. A. Ackerman, A. S. Bachmeier, and R. M. Rabin, 2007: A Quantitative analysis of the enhanced-V feature in relation to severe weather. Wea. Forecasting, 22, 853-872. CrossRef. 
Dvorak, V., 1984: Tropical Cyclone Intensity Analysis Using Satellite Data. NOAA Tech. Report NESDIS 11 NOAA/ NESDIS, 47 pp. [Available online at: $\underline{\text { severe. }}$ worldweather.wmo.int/TCFW/RAI Training/ Dvorak 1984.pdf]

Dworak, R., K. Bedka, J. Brunner, and W. Feltz, 2012: Comparison between GOES-12 overshooting-top detections, WSR-88D radar reflectivity, and severe storm reports. Wea. Forecasting, 27, 3, 684-699. CrossRef.

Goodman, S. J., T. J. Schmit, J. Daniels, W. Denig, and K. Metcalf, 2017. GOES: Past, Present, and Future. Reference Module in Earth Systems and Environmental Sciences, 1, 119-149. [Available online at: $\quad$ www.sciencedirect.com/science/article/pii/ B978012409548910315X]

Goodman, S. J., R. J. Blakeslee, W. J. Koshak, D. Mach, J. Bailey, D. Buechler, L. Carey, C. Schultz, M. Bateman, E. McCaul Jr., G. Stano, 2013: The GOES-R Geostationary Lightning Mapper (GLM), Atmos. Res., 125-126, 34-49. CrossRef.

Gravelle, C. M., J. R. Mecikalski, W. E. Line, K. M. Bedka, R. A. Petersen, J. M. Sieglaff, G. T. Stano, and S. J. Goodman, 2016: Demonstration of GOES-R satellite convective toolkit to "bridge the gap" between severe weather watches and warnings: an example from the 20 May 2013 Moore, Oklahoma, tornado outbreak, Bull. Amer. Meteor. Soc., 97, 69-84. CrossRef.

Greenwald, T., and Coauthors, 2015: Real-time simulation of the GOES-R ABI for user readiness and product evaluation. Bull. Amer. Meteor. Soc., 97, 245-261, CrossRef.

Kalluri, S., J. Gundy, B. Haman, A. Paullin, P. Van Rompay, D. Vititoe, A. Weiner, 2015: A high performance remote sensing product generation system based on a service oriented architecture for the next generation of Geostationary Operational Environmental Satellites. Remote Sens., 7 (8), 10385-10399. CrossRef.

Lindley, T. T., A. R. Anderson, V. N. Mahale, T. S. Curl, W. E. Line, S. S. Lindstrom, and A. S. Bachmeier, 2016: Wildfire detection notifications for impact-based decision support services in Oklahoma using geostationary super rapid scan satellite imagery. J. Operational Meteor., 4 (14), 182-191. CrossRef.

Liew, S. C., 2001: Principles of Remote Sensing, Centre for Remote Imaging, Sensing and Processing, [Available online at: crisp.nus.edu.sg/ research/tutorial/opt int. $\underline{\mathrm{htm}}$.

Line, W., T. J. Schmit, D. Lindsey, 2016: Use of geostationary rapid scan imagery by the Storm Prediction Center. Wea. Forecasting, 31, 483-494. CrossRef.

Lee, Y.-K., Z. Li, J. Li, and T. J. Schmit, 2014: Evaluation of the GOES-R ABI LAP retrieval algorithm using the GOES-13 sounder. Journal of Atmospheric and Oceanic Technology. 31, 3-19. CrossRef.
Lindsey, D. T., L. Grasso, J. F. Dostalek, and J. Kerkmann, 2014: Use of the GOES-R Split-Window Difference to diagnose deepening low-level water vapor. J. Appl. Meteor. Climatol., 53, 2005-2016, CrossRef

Lindsey D. T., T. J. Schmit, W. M. MacKenzie, C. P. Jewett, M. M. Gunshor, L. Grasso, 2012: $10.35 \mu \mathrm{m}$ : an atmospheric window on the GOES-R Advanced Baseline Imager with less moisture attenuation. J. Appl. Remote Sens., 6 (1), 063598. CrossRef.

Pavolonis, M. J., A. K. Heidinger, and J. Sieglaff,, 2013: Automated retrievals of volcanic ash and dust cloud properties from upwelling infrared measurements. Journal of Geophysical Research-Atmospheres, 118 (3), 1436-1458. CrossRef.

McCann, D. W., 1983: The enhanced-V: A satellite observable severe storm signature. Mon. Wea. Rev., 111, 887-894. CrossRef.

Miller, S. D., T. J. Schmit, C. J. Seaman, D. T. Lindsey, M. M. Gunshor, R. A. Kohrs, Y. Sumida, and D. Hillger, 2016: A Sight for sore eyes : the return of true color to geostationary satellites, Bull. Amer. Meteor. Soc, 97, 1803-1816. CrossRef.

Miller, S. D., C. C. Schmidt, T. J. Schmit, and D. W. Hillger, 2012: Acase for natural colour imagery from geostationary satellites, and an approximation for the GOES-R ABI. Int. J. Remote Sens., 33, 3999-4028, CrossRef.

Mecikalski, J. R., C. P. Jewett, J. M. Apke, and L. D. Carey, 2015: Analysis of cumulus cloud updrafts as observed with 1-min resolution super rapid scan GOES imagery. Mon. Wea. Rev., 144, 811-830. CrossRef.

Setvák, M., K. Bedka, D. T. Lindsey, A. Sokol, Z. Charvát, J. Št'ástka, and P. K .Wang, 2013: A-Train observations of deep convective storm tops. Atmos. Res., 123, 229 248, CrossRef.

Schmetz, J., P. Pili, S. Tjemkes, D. Just, J. Kerkmann, S. Rota, and A. Ratier, 2002: An introduction to Meteosat Second Generation (MSG). Bull. Amer. Meteor. Soc., 83, 977992. CrossRef.

Schmit, T. J., P. Griffith, M. M. Gunshor, J. M. Daniels, S. J. Goodman, and W. J. Lebair, 2017: A closer look at the ABI on the GOES-R Series. Bull. Amer. Meteor. Soc., Volume 98, Issue 4. 681-698. CrossRef.

, T. J., and Coauthors, 2014: Rapid refresh information of significant events: preparing users for the next generation of geostationary operational satellites, Bull. Amer. Meteor. Soc., 96, 561-575, CrossRef.

, T. J., and Coauthors, 2013: Geostationary Operational Environmental Satellite (GOES)-14 super rapid scan operations to prepare for GOES-R. J. Appl. Remote Sens., 7 (1), 073462. CrossRef.

, T. J., M. M. Gunshor, W. P. Menzel, J. J. Gurka, J. Li, S. Bachmeier, 2005: Introducing the next-generation Advanced Baseline Imager (ABI) on GOES-R. Bull. Amer. Meteor. Soc., 8, 1079-1096. CrossRef. 
, T. J., W. F. Feltz, W. P. Menzel, J. Jung, A. P. Noel, J. N. Heil, J. P. Nelson III, and G. S. Wade, 2002: Validation and use of GOES sounder moisture information. Weather and Forecasting, 17, 139-154. CrossRef.

Sieglaff, J. and T. J. Schmit, 2003: Vegetation monitoring and thin cirrus detection on the next generation GOES imager. 12th Conference on Satellite Meteorology and Oceanography, American Meteorological Society, Long Beach, CA. [Available online at: ams.confex.com/ams/ annual2003/webprogram/Paper54819.html]

Smith, T. M., and Coauthors, 2016: Multi-Radar MultiSensor (MRMS) severe weather and aviation products: initial operating capabilities. Bull. Amer. Meteor. Soc., 97, 1617-1630, CrossRef.

Strabala, K. I., S. A. Ackerman, and W. P. Menzel, 1994: Cloud properties inferred from 8-12 um data, J. Appl. Meteorol., 33, 212-229. CrossRef.

Tucker, C. J., 1979: Red and photographic infrared linear combinations for monitoring vegetation, Remote Sensing of Environment, 8 (2), 127-150. CrossRef.

Wimmers, A, S. Griffin, J. Gerth, S. Bachmeier, S. Lindstrom, 2018: Observations of gravity waves with high-pass filtering in the new generation of geostationary imagers and their relation to aircraft turbulence, Wea. Forecasting, 33, 139-144. CrossRef.

Yung, Y. L., 2003: Book Review: An Introduction to Atmospheric Radiation. Q.J.R. Meteorol. Soc., 129, 1741. $\underline{\text { CrossRef. }}$.

Zavodsky, B. T., A. L. Molthan, and M. J. Folmer, 2013: Multispectral imagery for detecting stratospheric air intrusions associated with mid-latitude cyclones. J. Operational Meteor., 1 (7), 71-83, CrossRef. 